\title{
The Use of Lignin as Cross-linker for Polyurethane Foam for Potential Application in Adsorbing Materials
}

\author{
Jinpeng Li, Bin Wang,* Kefu Chen, ${ }^{*}$ Xiaojun Tian, Jinsong Zeng, Jun Xu, and \\ Wenhua Gao
}

\begin{abstract}
Lignin was extracted from wheat straw and used for its crosslinking function in the synthesis of polyurethane foam (PUF). The effects of lignin's addition on the cross-linking structure and macroscopic properties of the PUFs were investigated. A morphological examination, Fourier transform infrared (FT-IR) spectroscopy, and thermogravimetric analysis (TGA) were conducted to measure the performance of the polyurethanes. Kinetic models were simulated to analyze the oily solvent adsorption mechanism of the polyurethane. The results showed that an increase in the cross-linking density was conducive to an improvement of the physical properties of the polyurethane. Moreover, the process of oily solvent adsorption was in accordance with the quasi-second-order kinetic model. Both physical and chemical adsorption occurred during the adsorption process. This work demonstrated a highly effective method for imparting PUFs with an excellent performance and proper lignin content.
\end{abstract}

Keywords: Polyurethane foam; Lignin; Cross-linking; Mechanical properties; Kinetic model

Contact information: Plant micro/nano fiber research center, State Key Laboratory of Pulp and Paper Engineering, School of Light Industry and Engineering, South China University of Technology, Guangzhou 516640, China; *Corresponding authors: febwang@scut.edu.cn; ppchenkf@scut.edu.cn

\section{INTRODUCTION}

Recently, the utilization of sustainable and environmentally friendly sources for the production of green materials has generated noticeable interest from both academic and industrial fields. Of these renewable resources, biomass acts as a carbon source that can generate valuable chemicals and replace petrochemicals. The production of new valueadded bio-chemicals and biomaterials from various types of industrial or agricultural residual resources was proposed by use of bio-refining approaches (Li et al. 2016).

Lignin is a complex, heterogeneous, and natural aromatic compound that contains cross-linked phenolic polymers (Jeong et al. 2013). However, lignin is only a byproduct in the paper-making industry and is most often burned as a low-value fuel. As a source of chemicals and materials, lignin can replace petroleum feedstock for many polymer products (Mahmood et al. 2016b). Different functional monomers (phenolic hydroxyl, aliphatic hydroxyl, and methoxyl groups) are incorporated in the macromolecular phenyl propane structure (Baillères et al. 1997; Vanholme et al. 2010). The rigid benzene ring structure and phenol hydroxyl groups in the lignin structure are promising candidates for value-added utilization (Li and Ragauskas 2012).

One method for the value-added utilization of lignin is to prepare lignin-containing copolymers (Saito et al. 2013). A strategic execution of copolymerization is to prepare polyurethane foams (PUFs). The PUFs are considered to be one of the most versatile and useful three-dimensional polymeric materials with applications in diverse areas, and are an 
important category of expended materials (Hatakeyama et al. 2008; Cateto et al. 2014). Polyurethane foams can be applied in many areas, including as sponges in furniture manufacturing, wastewater treatment, packaging, sound absorbing materials, adhesives, etc. (dos Santos et al. 2013; Huo et al. 2012; Kumari et al. 2016).

The reactions between polyols and isocyanates during the chain propagation steps play an important role in the polymerization reactions when preparing polyurethane (Li et al. 2016). The lignin in polyurethane is mainly used as an additive packing/filler (Paberza et al. 2014), reactive agent to be cross-linked with urethane (Pan and Saddler 2013), and modified functional additive (Zhu et al. 2014). Cinelli et al. (2013) reported a green process for the synthesis of soft PUFs using kraft lignin with two types of chain extenders, which can impart PUFs with a higher flexibility. Li et al. (2016) noted that alkaline lignin was completely liquefied with polyethylene glycol-400/glycerol when preparing PUFs with higher thermal and physical performances. Jeong et al. (2013) used softwood kraft lignin as a cross-linking agent to react with polyol when preparing PUFs. The obtained PUFs showed an excellent elasticity and could be used in buffer materials.

Using lignin as an additional agent to prepare PUFs has been widely studied (Xue et al. 2014; Carriço et al. 2016; Mahmood et al. 2016a). The additive amount of lignin in earlier works were all higher than 5\%, and amounts in excess of that cause agglomeration of lignin particles in the final products. It has been shown that micro-additive amounts of functional reagents can lead to a remarkable improvement of the mechanical characteristics of cross-linked polyurethane (Estrin et al. 2012). The relationship between the lignin content and cross-linking behavior has rarely been studied.

The present research investigates the effect of micro lignin contents on the crosslinking structure and physical properties of prepared lignin-based polyurethane foam (LPUF). At the same time, the physical performance, mechanical properties, and thermal behaviors were evaluated. Finally, the adsorptive properties of the LPUFs were thoroughly investigated.

\section{EXPERIMENTAL}

\section{Materials}

Lignin was extracted from the black liquor of wheat straw. The relevant data of the lignin and a more detailed description of the pulping conditions are given in the authors' previous work (Tian et al. 2017).

The chemical 4,4'-methylenebis phenyl isocyanate (MDI, purity $\geq 98 \mathrm{wt} . \%$ ) was purchased from Aladdin (Shanghai, China). Polyethylene glycol (PEG, 330n, molecular weight $=5000 \mathrm{~g} / \mathrm{mol}, \mathrm{OH}=33$ to $37 \mathrm{mg} \mathrm{KOH} / \mathrm{g}$ ) was provided by Hengyu Chemical Co., Ltd. (Jiangsu, China). Silicone oil (Industrial reagent, IR) was supplied by Scientific and Technological Chemical Technology Co., Ltd. (Beijing, China). Benzene, toluene, xylene, ethyl acetate, triethanolamine, and dibutyltin dilaurate were all used as analytical reagents. Ultrapure water $(18 \mathrm{M} \Omega \cdot \mathrm{cm}$ at $298 \mathrm{~K}$ ) was purified with a Millipore Milli-Q (Millipore Direct-Q5, Billerica, MA, USA). 


\section{Synthesis of the lignin-based polyurethane foam (LPUF)}

The PEG $(20.00 \mathrm{~g})$ and lignin (lignin weight present was based on the weight of PEG: $0 \%, 0.5 \%, 1 \%, 1.5 \%, 2 \%, 2.5 \%$ ) were weighed, added to a 50 -mL plastic beaker, and magnetically stirred at $25{ }^{\circ} \mathrm{C}$ for $5 \mathrm{~min}$ to obtain a uniform pre-mixture. The premixture, deionized water $(0.35 \mathrm{~g})$, triethanolamine $(0.20 \mathrm{~g})$, silicone oil $(0.40 \mathrm{~g})$, and dibutyltin dilaurate $(0.15 \mathrm{~g})$ were accurately weighed, and stirred in a thermostat water bath at $80{ }^{\circ} \mathrm{C}$ for $5 \mathrm{~min}$. The MDI $(8.0 \mathrm{~g})$ was added into the mixture under constant stirring conditions. The mixture was immediately poured into a mold (cubic paper container, $10 \times$ $10 \times 8 \mathrm{~cm}^{3}$ ) where the mixture emitted heat and produced bubbles. Finally, the LPUFs were obtained after heating the mold for $10 \mathrm{~h}$ at $80^{\circ} \mathrm{C}$. A better isocyanate index was 1.1 , which was reported in previous studies (Pan and Saddler 2013; Carriço et al. 2016). The isocyanate index was calculated according to the following formula (Cinelli et al. 2013),

$$
\frac{n_{[\mathrm{NCO}]}}{n_{[\mathrm{OH}]}}=\frac{W_{\mathrm{NCO}} \times W_{\mathrm{NCO}}}{\sum W_{O H} \times M_{O H}+\frac{2}{18} \times W_{\mathrm{H}_{2} O}}
$$

where $n_{[\mathrm{NCO}]}$ and $n_{[\mathrm{OH}]}$ are the amounts of isocyanate and PEG (mol), respectively, $W_{N C O}$ and $W_{O H}$ are the weight of the isocyanate and polyol (containing PEG, lignin, and catalysts) $(\mathrm{g})$, respectively, $M_{N C O}$ and $M_{O H}$ are the molar masses of isocyanate and polyol $(\mathrm{mol} / \mathrm{g})$, respectively, and $W_{\mathrm{H}_{2} \mathrm{O}}$ is the mass of the water $(\mathrm{g})$.

\section{Cross-linking density}

The cross-linking density was calculated by the Flory-Rehner equation, which is given as Eq. 2 (Flory and Rehner 1943; Zhu et al. 2011),

$$
-\left[\ln \left(1-\mathrm{v}_{\mathrm{p}}\right)+\mathrm{v}_{\mathrm{p}}+\chi \mathrm{v}_{\mathrm{p}}^{2}\right]=\mathrm{v}_{\mathrm{s}} \rho_{\mathrm{p}}\left(\mathrm{v}_{\mathrm{p}}^{1 / 3}-\frac{\mathrm{v}_{\mathrm{p}}}{2}\right) / \mathrm{M}_{\mathrm{e}}
$$

where $v_{\mathrm{p}}$ is the volume of the polymer in the swollen PUFs $(\%), \chi$ is the interaction parameter of the polymer-solvent, $v_{\mathrm{s}}$ is the molar volume of the solvent (\%), and $M_{\mathrm{e}}$ is the average relative molecular mass between adjacent cross-links $(\mathrm{g} / \mathrm{mol})$.

Equation 2 is frequently rearranged and simplified, and is shown below as Eq. 3 (Fan and Xiao 2010),

$$
\mathrm{V}_{\mathrm{e}}=-\frac{1}{\mathrm{v}_{\mathrm{s}}}\left[\frac{\ln \left(1-\mathrm{v}_{\mathrm{p}}\right)+\mathrm{v}_{\mathrm{p}}+\chi \mathrm{v}_{\mathrm{p}}^{2}}{\mathrm{v}_{\mathrm{p}}^{1 / 3}-\mathrm{v}_{\mathrm{p}} / 2}\right]
$$

where $V_{\mathrm{e}}$ is the cross-linking density of the polyurethane $\left(\mathrm{mol} / \mathrm{cm}^{3}\right)$. The variables $v_{\mathrm{p}}$ and $\chi$ were determined by Eqs. 4 and 5, respectively (Zhu et al. 2011),

$$
\begin{aligned}
& v_{p}=\frac{m_{p} / \rho_{p}}{m_{p} / \rho_{p}+m_{s} / \rho_{s}} \times 100 \% \\
& \chi=\frac{v_{\mathrm{s}}}{R T}\left(\delta_{\mathrm{p}}-\delta_{\mathrm{s}}\right)^{2}
\end{aligned}
$$

where $m_{\mathrm{p}}$ and $m_{\mathrm{s}}$ represent the masses of the polyurethane and solvent $(\mathrm{g})$, respectively, $\rho_{\mathrm{p}}$ and $\rho_{\mathrm{s}}$ are the densities of the polyurethane and solvent $\left(\mathrm{g} / \mathrm{cm}^{3}\right)$, respectively, $R$ and $T$ are the gas constant $(8.314 \mathrm{~J} / \mathrm{K} \cdot \mathrm{mol})$ and absolute temperature $(\mathrm{K})$, respectively, and $\delta_{s}$ is the solubility parameter of the solvent $\left(\mathrm{J} / \mathrm{cm}^{3}\right)$. The variable $\delta_{\mathrm{p}}\left(\mathrm{J} / \mathrm{cm}^{3}\right)$ was determined by fitting the curves of the swelling coefficients $(\mathrm{Q})$ versus the solubility parameter $(\delta)$ (Mathew et al. 2017). The corresponding abscissa value at the top of the curve was determined as $\delta_{\mathrm{p}}$ in Fig. 3. (a). 


\section{Methods}

Fourier transform infrared (FT-IR) spectroscopy

The Fourier transform infrared (FT-IR) spectra of the PUFs were recorded using a VERTEX-70 (Bruker, Karlsruhe, Germany) equipped with a digital detector. The dry samples were ground and pelletized using $\mathrm{KBr}$. The spectra were then measured in the wavenumber range of $4000 \mathrm{~cm}^{-1}$ to $400 \mathrm{~cm}^{-1}$.

\section{Apparent density}

The apparent density was determined according to the standard ASTM D792 (2008). The samples were measured five times, and the average results were recorded.

\section{Mechanical properties}

The mechanical properties tests were performed with an Instron instrument (model 5565, Norwood, GA, USA). The tensile and compressive tests were carried out according to ASTM D1623-09 (2009) and ASTM D1621-10 (2010) (Hakim et al. 2011; Yu et al. 2014), respectively. Both the tensile and compression tests of PUFs/LPUFs were performed at the room $\left(25^{\circ} \mathrm{C}\right)$ and the rate of the crosshead movement was fixed at 10 $\mathrm{mm} / \mathrm{min}$. The specimens were evaluated five times, and the average values were determined.

\section{Thermogravimetric analysis (TGA)}

Thermogravimetric analysis (TGA) was performed using a TA Q500 apparatus (TA Instrument, New Castle, USA) under a nitrogen gas atmosphere. The samples were heated from room temperature to $700{ }^{\circ} \mathrm{C}$ at a heating rate of $10{ }^{\circ} \mathrm{C} / \mathrm{min}$.

\section{Adsorption tests}

The methods for determination of the oily solvent and water sorption were based on the ASTM F726-99 (1999) standard test method (Li et al. 2012). Four types of oily solvent, benzene, methyl benzene, dimethyl benzene, and ethyl acetate, were employed to investigate the adsorption quantity of the sorbents. The sorbent was cut to the specified size and weighed accurately to determine the initial mass. Different oily solvents $(50 \mathrm{~mL})$ were poured into a $100-\mathrm{mL}$ beaker. After immersion for $30 \mathrm{~min}$, the specimen was removed and weighed immediately after it was drained for $30 \mathrm{~s}$. The experimental error was controlled within plus or minus $5 \%$, and the sorption was calculated by Eq. 6 ,

$$
\operatorname{Sorption}(\mathrm{g} / \mathrm{g})=\frac{S_{0 \mathrm{t}}-S_{0}}{S_{0}}
$$

where $S_{0}$ is the initial weight of the sorbent ( $\mathrm{g}$ ) and $S_{\mathrm{ot}}$ is the weight of the sorbent that has adsorbed oily solvent $(\mathrm{g})$.

\section{Kinetic model analysis}

Lagergren quasi-first-order and quasi-second-order kinetic equations were used to analyze the polyurethane oily solvent adsorption process. The two model algorithms are shown by Eqs. 7 and 8 (Qiu et al. 2009; Huo et al. 2012),

$$
\begin{aligned}
& \log \left(Q_{e}-Q_{t}\right)=\log Q_{e}-\frac{K_{1} t}{2.303} \\
& \frac{t}{Q_{t}}=\frac{1}{K_{2} Q_{e}^{2}}+\frac{t}{Q_{e}}
\end{aligned}
$$


where $Q_{\mathrm{e}}$ and $Q_{\mathrm{t}}$ are the amounts of solvent adsorbed $(\mathrm{g} / \mathrm{g})$ at the equilibrium and time $t$ (min), respectively, and $K_{1}$ and $K_{2}$ are the adsorption constants corresponding to the quasifirst-order $\left(\mathrm{min}^{-1}\right)$ and quasi-second-order $(\mathrm{g} / \mathrm{g} \mathrm{min})$ kinetic equations, respectively.

The kinetic evaluation of the adsorption was also performed by using Morris-Weber model to explain the diffusion process (Qiu et al. 2009). The Morris-Weber model was described by Eq. 9 ,

$$
Q_{\mathrm{t}}=k_{\mathrm{d}} \cdot t^{1 / 2}+C
$$

where $k_{\mathrm{d}}$ is the intraparticle diffusion constant. $C$ represents a parameter of the function that indicated the resistance of the interfacial film (Crini et al. 2007).

\section{RESULTS AND DISCUSSION}

\section{FT-IR}

Figure 1 shows the FT-IR spectra of lignin and PUFs. Pristine lignin showed a broad band at $3500-3000 \mathrm{~cm}^{-1}$, which was attributed to the stretching of phenolic and aliphatic hydroxyl groups (Kumari et al. 2016). The absorption peak at $2970 \mathrm{~cm}^{-1}$ was associated with the $\mathrm{C}=\mathrm{O}$ stretching vibration in carbonyl groups. The bonds at $2922 \mathrm{~cm}^{-1}$ were related to asymmetric stretching vibration of methylene $\left(-\mathrm{CH}_{2}\right)$ and $2848 \mathrm{~cm}^{-1}$ were due to $\mathrm{C}-\mathrm{H}$ symmetric stretching vibration in lignin molecular structure (Yang et al. 2015). The bands at $1622 \mathrm{~cm}^{-1}, 1508 \mathrm{~cm}^{-1}$, and $1460 \mathrm{~cm}^{-1}$ resulted from aromatic ring stretching vibration.

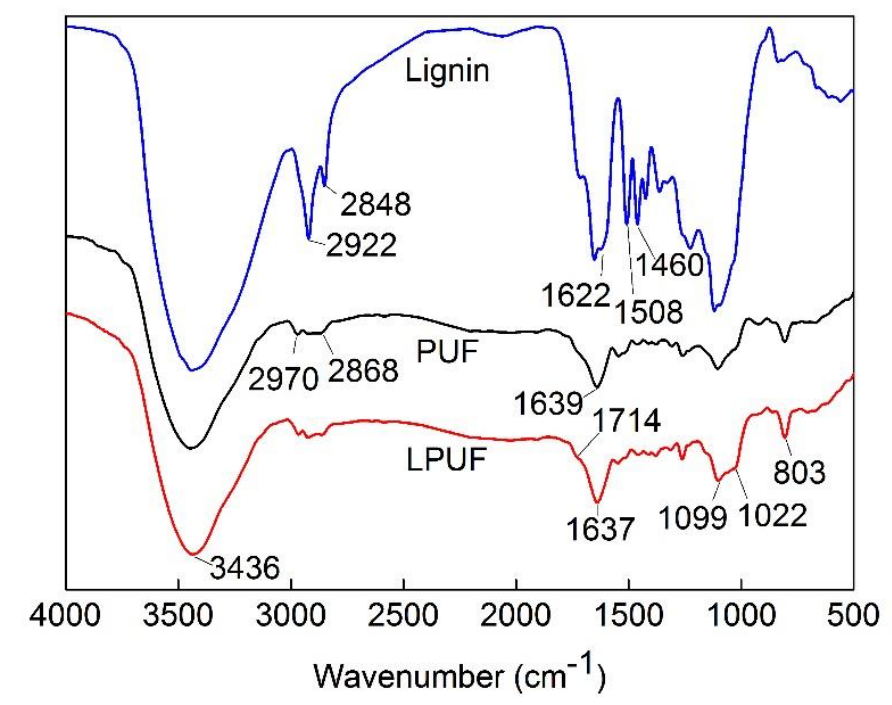

Fig. 1. FT-IR spectra of lignin, PUF and LPUF (0.5 wt.\% lignin)

From the spectra of polyurethane foams, the characteristic absorption peaks that appeared at approximately $3436 \mathrm{~cm}^{-1}$ were assigned to the stretching vibration of the N-H bond (Santos et al. 2016) in polyurethane. The bands centered approximately $2970 \mathrm{~cm}^{-1}$ and $2868 \mathrm{~cm}^{-1}$ corresponded to the C-H stretching of the aliphatic chains (Rahman et al. 2016). The vibrancy peak observed near $1714 \mathrm{~cm}^{-1}$ were associated with carbonyl stretching. The peak at $1637 \mathrm{~cm}^{-1}$ was the characteristic absorption of urea. The bonds between $1022 \mathrm{~cm}^{-1}$ and $1099 \mathrm{~cm}^{-1}$ were ascribed to the $\mathrm{C}-\mathrm{O}$ bond (Qu et al. 2017). The 
signal that appeared at $803 \mathrm{~cm}^{-1}$ was attributed to the $\mathrm{C}-\mathrm{H}$ deformation of the aromatic groups in the spectra. The reaction between isocyanate and lignin was evidenced by the following changes of FTIR spectra: (a) a wider band at $3436 \mathrm{~cm}^{-1}$ in polyurethane typical of bonded N-H increased with increasing lignin content, which was merged with the $\mathrm{OH}$ bond at $3300 \mathrm{~cm}^{-1}$ (Luo et al. 2013); (b) a marked increase of the absorption bands in $\mathrm{C}-\mathrm{O}$ stretching region between $1022 \mathrm{~cm}^{-1}$ and $1099 \mathrm{~cm}^{-1}$ was due to the reaction between isocyanate and hydroxyl groups of lignin; (c) the peaks of urea shifted from $1639 \mathrm{~cm}^{-1}$ to $1637 \mathrm{~cm}^{-1}$ suggesting that the introduction of lignin affect the hydrogen bonds between $\mathrm{N}$ $\mathrm{H}$ and $\mathrm{C}=\mathrm{O}$ because of the interaction between lignin and isocyanate (Carriço et al. 2016). It was concluded that the reaction occurred between isocyanate and lignin. In addition, the addition of lignin did not change the main functional groups of the PUFs, as was shown in the FT-IR spectra.

\section{Synthesis and Oily Solvent Adsorption of the Polyurethane Foams (PUFs)}

The synthetic reaction diagram of the PUFs is shown in Fig. 2. Because of the numerous hydroxyl groups and special three-dimensional structure, the lignin added can not only extend the polyurethane molecular chain, but it can also support a skeleton in a cellular structure. Hydrogen bonds also existed in the compound molecules. The unique spatial structure of lignin was beneficial for increasing the cross-linking density and improving the physical properties of polyurethanes.

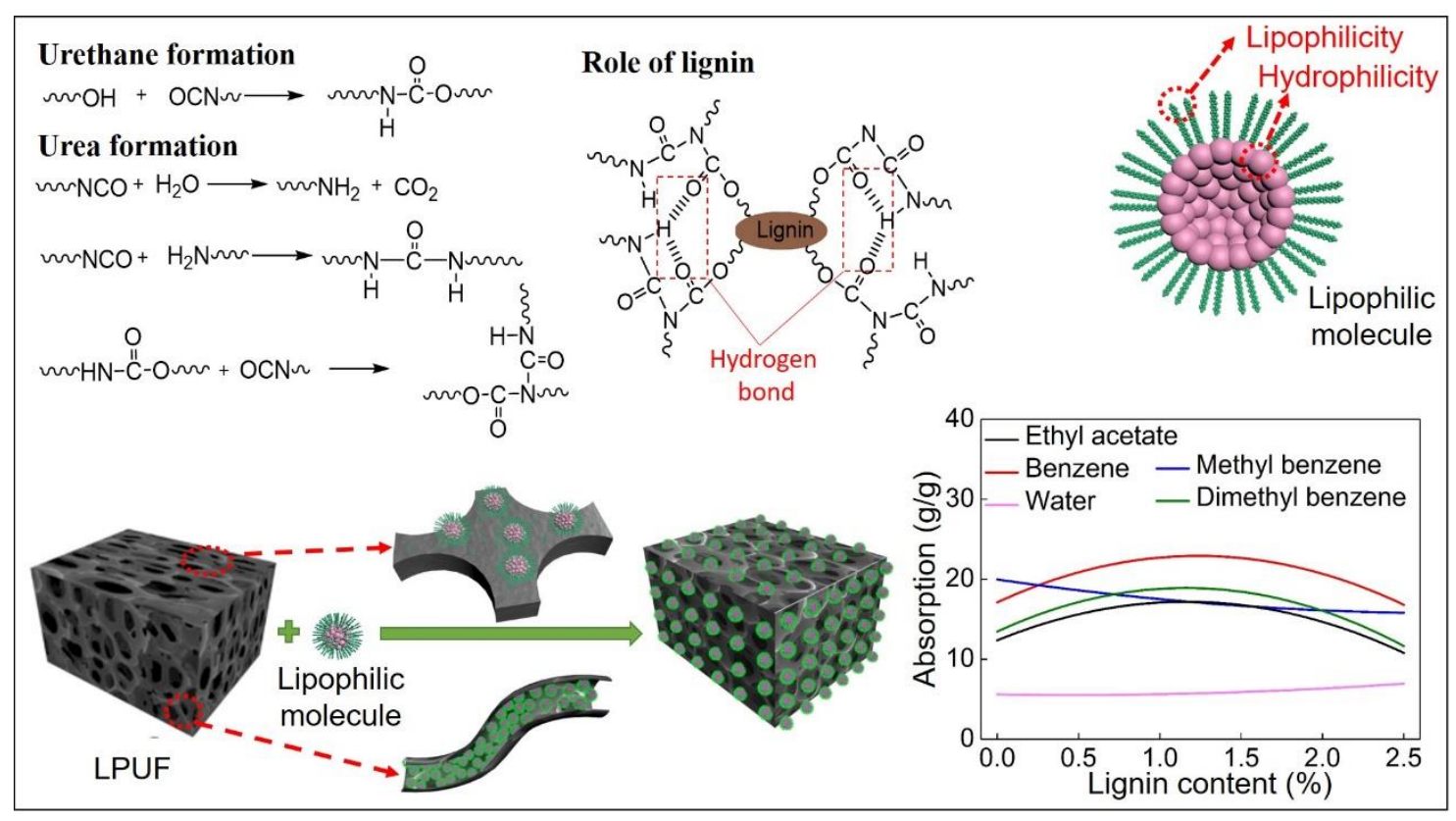

Fig. 2. Synthetic reaction and oily solvent adsorption diagram of the LPUF

The adsorption behavior of the oily solvents onto the LPUFs is also described in Fig. 2. The oily solvents were adsorbed onto the surface of the PUFs via van der Waals forces through lipophilic oily molecules. Oleophilic and hydrophobic groups, such as aroma structures, ether bonds, ester bonds, and hydrocarbon side chains, are introduced in condensation polymerization reactions. These groups exist on the surface of the foams and promote intermolecular attraction, which can enhance the oily solvent adsorptive capacity (Gui et al. 2011; Li et al. 2012). Electron transfer occurs between an adsorbent and 
adsorbate during chemical adsorption and promotes the formation of new chemical bonds. When the lignin content was in the range of $0.5 \mathrm{wt} . \%$ to $2.0 \mathrm{wt} . \%$, the maximum adsorption of benzene, dimethyl benzene, and ethyl acetate increased by $50.2 \%, 44.0 \%$, and $41.5 \%$, respectively, compared with that with no lignin addition.

\section{Cross-linking Density of the PUFs}

The swelling coefficients $\left(Q=1 / \nu_{\mathrm{p}}\right)$ versus the solubility parameters $(\delta)$ of the LPUFs with different lignin contents are shown in Fig. 3 (a). The corresponding abscissa values at the top of the curves were fitted by Gauss and were determined as the solubility parameter (Valero et al. 2009; Mathew et al. 2017).
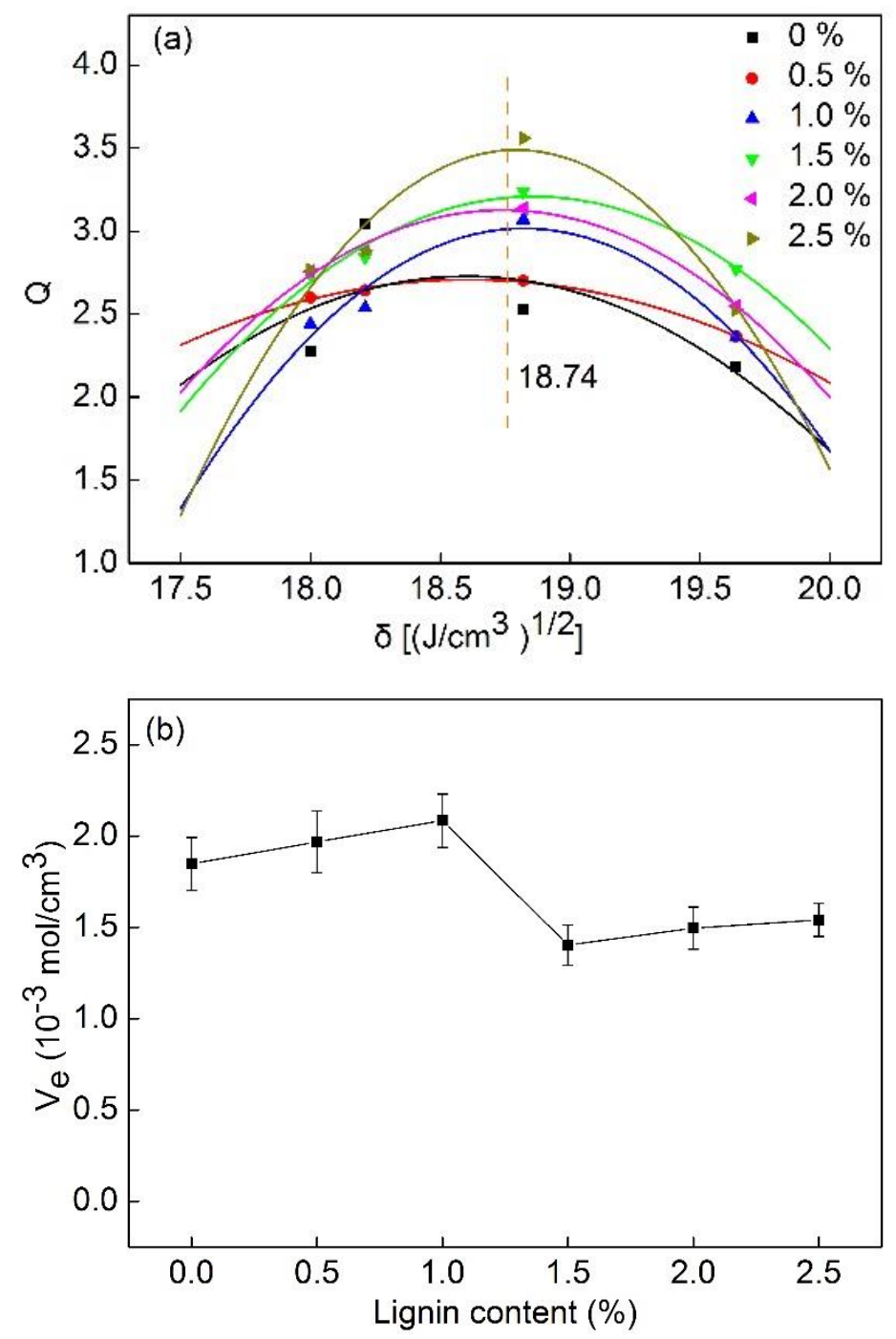

Fig. 3. (a) Fitting curves of the swelling coefficients $(Q)$ versus the solubility parameters $(\delta)$ of the LPUFs with different lignin contents; (b) cross-linking density of the LPUFs

It was found that the abscissa corresponding to the maximum value of the ordinate was $18.7\left(\mathrm{~J} / \mathrm{cm}^{3}\right)^{1 / 2}$ (Zhu et al. 2011). The cross-linking density of PUFs were calculated by Eq. (3), (4), and (5). The cross-linking densities of the PUFs showed a slight increase with lignin content less than $1 \%$. The cross-linking density of the PUFs increased with a small 
addition of lignin (less than 1\%), but when the lignin content increased further, the crosslinking density decreased noticeably, as shown in Fig. 3b. This was possibly due to that the cross-linking reaction between the isocyanates and hydroxyl groups distributed on the surface of lignin macromolecules caused the enhancement of cross-linking values and promoted the formation of more complex network structures in polyurethanes. However, overused lignin may produce local excessive cross-linking due to agglomeration, which leads to a decrease in the cross-linking density of PUF.

\section{SEM Analysis of PUFs}

The micrographs, mean pore diameter, and spatial network skeleton thickness derived from the normal PUF and LPUFs are presented in Fig. 4.
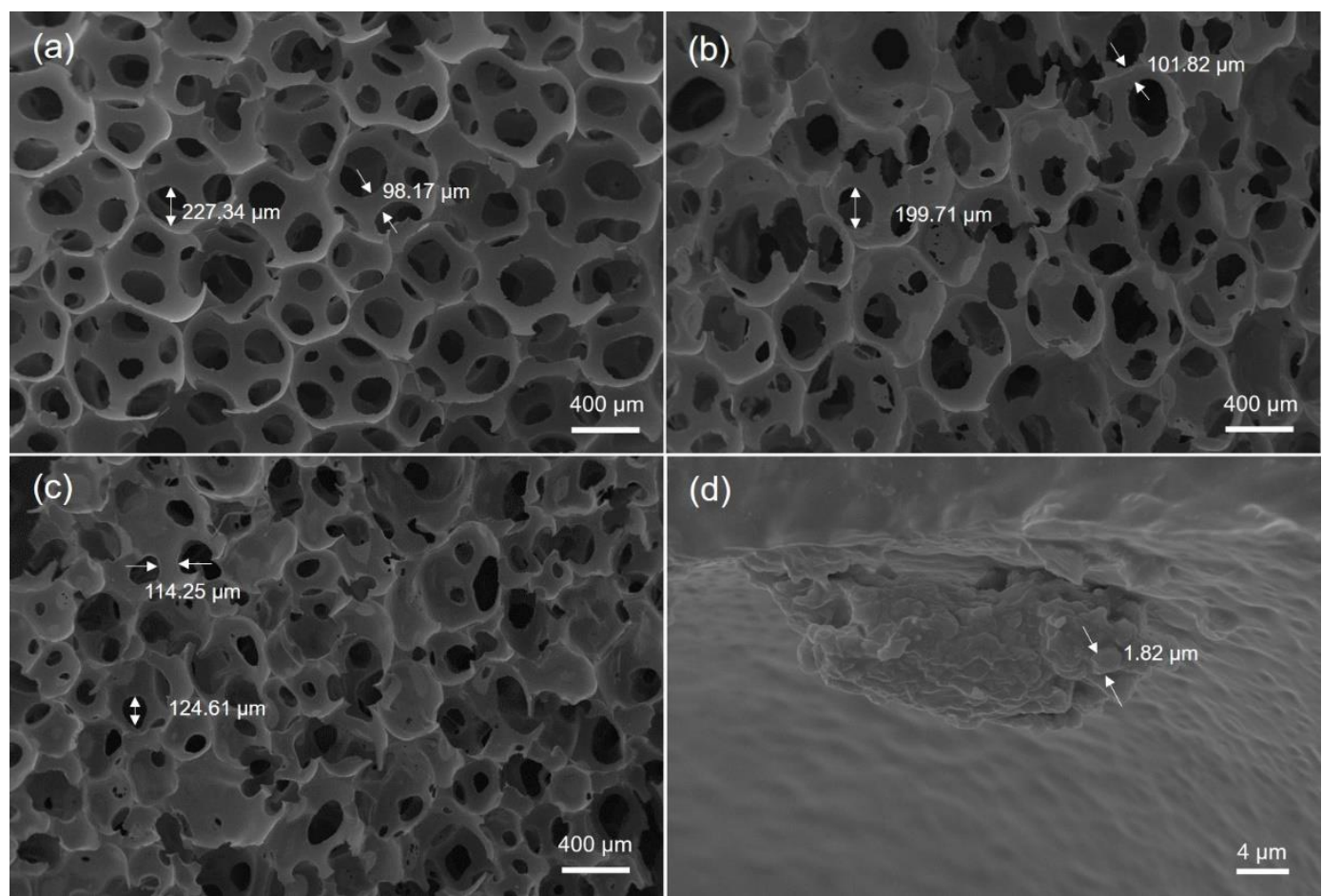

(d)
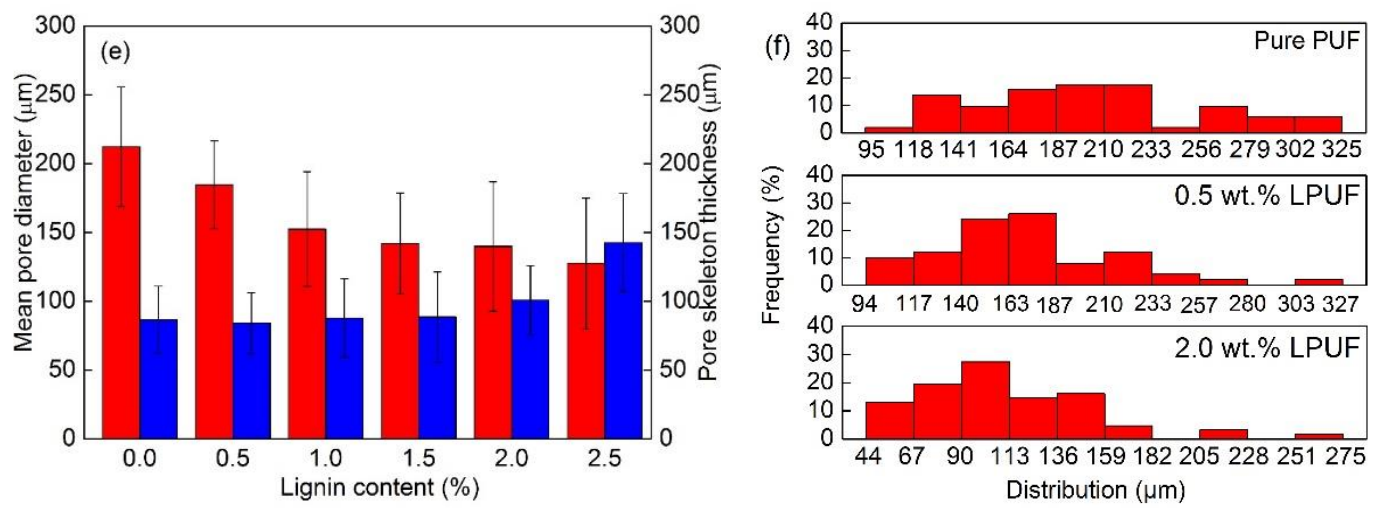

Fig. 4. Micro images of the PUFs: (a) pure PUF, (b) 0.5 wt.\% LPUF, (c) 2.0 wt.\% LPUF, and (d) flocculation of lignin; (e) mean pore diameter and spatial network skeleton thickness of the LPUFs (f) The pore size frequency distribution of pure PUF, $0.5 \mathrm{wt} . \%$ LPUF and $2.0 \mathrm{wt} . \%$ LPUF 
The pure PUF was relatively uniform and had larger open-pores, as shown in Fig. 4a. However, irregular and disorganized holes appeared when lignin was added. The pore size and structure of the PUF/LPUFs were closely related to the lignin content in the samples. The alteration in the interior spatial network and skeleton morphology was most likely because of the fact that lignin may affect the process of cell nucleation during the synthesis of polyurethane (Xue et al. 2014). The amount of lignin in the polyurethane has a great effect on the structure of the cells (Li et al. 2011). The irregular and inhomogeneous distribution of lignin in the LPUFs was attributed to the chemical bond attraction between the reactive chemical groups that persisted on the surface and the flocculant caused by the multidimensional mesh structure of natural lignin, which can be seen in Fig. 4d. A similar situation did not occur when the amount of lignin added was more than $1.5 \mathrm{wt} \%$. Smaller pores and a thicker cellular skeleton occurred in the LPUFs, as shown in Fig. 4e. The pore size frequency distribution of pure PUF, $0.5 \mathrm{wt} . \%$ LPUF and $2.0 \mathrm{wt} . \%$ LPUF are shown in Fig. 4f. It was found that larger pore size and wide distribution occurred in pure polyurethane foam, and the pore size was obviously reduced after blending lignin. Hence, more complex pores and thicker cellular skeleton were formed when added lignin in the PUFs. The observed smaller and more complex pores and thicker cellular skeleton can thus explain the improvement of the physical and mechanical properties. For cells with a similar wall thickness, the density increases as the cell size decreases, which influences the mechanical properties (Cateto et al. 2014).

\section{Mechanical Properties of the PUFs}

The apparent density of the PUFs is considered to be an important criterion for measuring its performance, and it affects the pore structure and mechanical properties of the PUFs (Dworakowska et al. 2014). With the addition of lignin, the apparent density of the polyurethane first decreased, and then it gradually increased, as shown in Fig. 5a. A possible explanation for the decreased density was that a small amount of lignin dispersed uniformly and crosslinked with the macromolecules in the LPUFs. This process promoted the formation of stable foam skeleton and bubble structures in the polyurethane. The foam structure was formed, and larger volumes and lower densities were obtained. Increasing the dosage of lignin to over $1 \mathrm{wt} \%$ resulted in local excessive cross-linking due agglomeration, which led to aggregation and adhesion of the lignin particles.

The elongation at break and specific compressive strength are also shown in Fig. 5. The results showed that the elongation at break increased slightly, and then decreased with increased amounts of lignin. The high values for the $0.5 \mathrm{wt} . \%$ lignin content were because of the polyol flexible segments. Once the lignin amount exceeded $1 \mathrm{wt} . \%$, the elongation at break decreased noticeably.

According to Fig. 5b, the compressive and specific compressive strengths of the LPUF with a 0.5 wt.\% lignin content were both higher than for the pure PUF. The compressive strength of the $0.5 \mathrm{wt} . \%$ LPUF increased $40.8 \%$, and the specific compressive strength increased $61.3 \%$ compared with the pure PUF.

The following reasons explained the enhancement of the physical behaviors: (1) plasticized lignin decreases the cross-linking density of LPUFs, which increases the apparent density and compressive strength (Zhang et al. 2015); (2) the natural rigid structure of lignin may disrupt the macromolecular structure, which decreases the elongation and enhances the physical properties (Putz et al. 2008); (3) the hydrogen bonding between $-\mathrm{NH}$ and $-\mathrm{C}=\mathrm{O}$ in LPUFs may cause a decrease in elongation, and Huang and Lai (1997) established that an increase in the hydrogen bonding index can increase the 
modulus and decrease the maximum elongation of LPUFs; and (4) the imbalance between the gel and foaming rates is caused by the excessive lignin content in the synthesis process, which leads to a decrease in the cross-linking density and seriously affects both the compressive and specific compressive strengths.
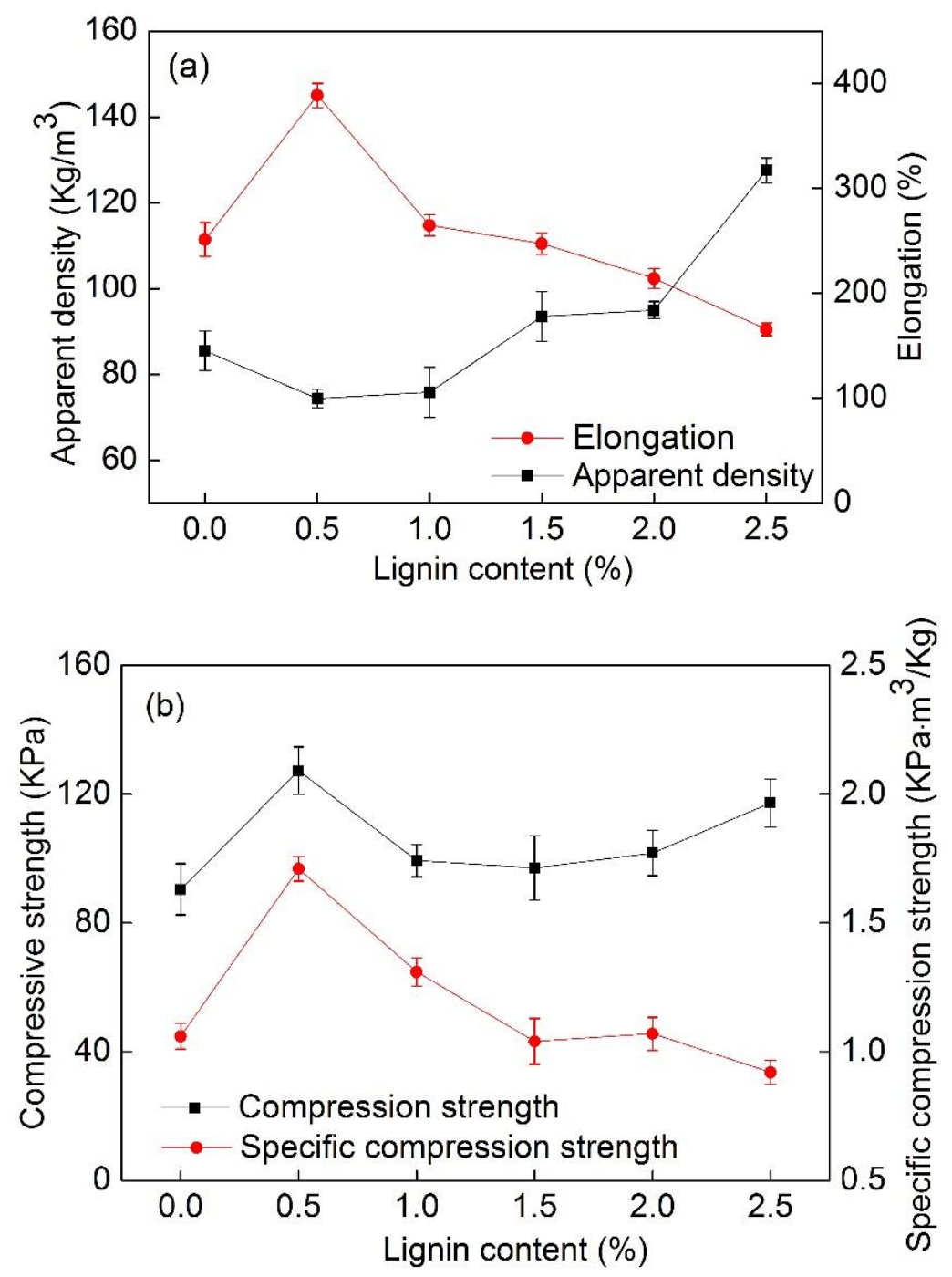

Fig. 5. (a) Apparent density and elongation of the polyurethanes; (b) compressive strength and specific compressive strength of the polyurethanes

\section{Thermal Gravimetric Analysis}

The TGA and DTG of lignin and PUFs were performed to investigate the effect of the lignin amount on the thermal behavior of the PUFs. It was observed that for lignin, the TGA curve of lignin showed a rapid mass loss before $150{ }^{\circ} \mathrm{C}$, which was due to higher moisture content in the sample. The final thermal degradation temperature of lignin was higher than that of PUF/LPUFs. Thermal degradation of the PUFs occurred in almost the same way in three steps, as shown in Fig. 6 (a) and (b). The initial mass loss at temperatures lower than $250{ }^{\circ} \mathrm{C}$ was attributed to the evaporation of water and the loss of some small organic molecules in the PUFs (Carriço et al. 2016). The second mass loss observed at approximately $305^{\circ} \mathrm{C}$ was related to the decomposition of hard segments urethane groups. 
The third degradation event at $372{ }^{\circ} \mathrm{C}$ was probably due to the depletion of C-C bonds (Santos et al.2016). Moreover, the skeleton of the foam was arranged to be more compact, due to the change of crosslinking density and mobility of the polymer chains in PUFs. In addition, the degradation temperature for LPUF was higher because of the addition of lignin (Oribayo et al. 2017). As expected, the TGA thermograms and DTG curves confirmed that the thermal stability of the foam was improved after blending with lignin. According to Fig. $6 a$ and $b$, the thermogravimetric parameters of the PUFs shown in Table 1 , it was revealed that the thermal decomposition temperature of the PUFs was effectively improved by introducing lignin into the PUF system. A possible explanation for this was that the introduction of lignin molecules increased the cross-linking density during the reaction. Moreover, the skeleton of the foam was arranged to be more compact, which was related to the change of crosslinking density and mobility of the polymer chains in PUFs (Santos et al. 2016). It was concluded that the thermal resistance of PUFs was improved through the incorporation of lignin.
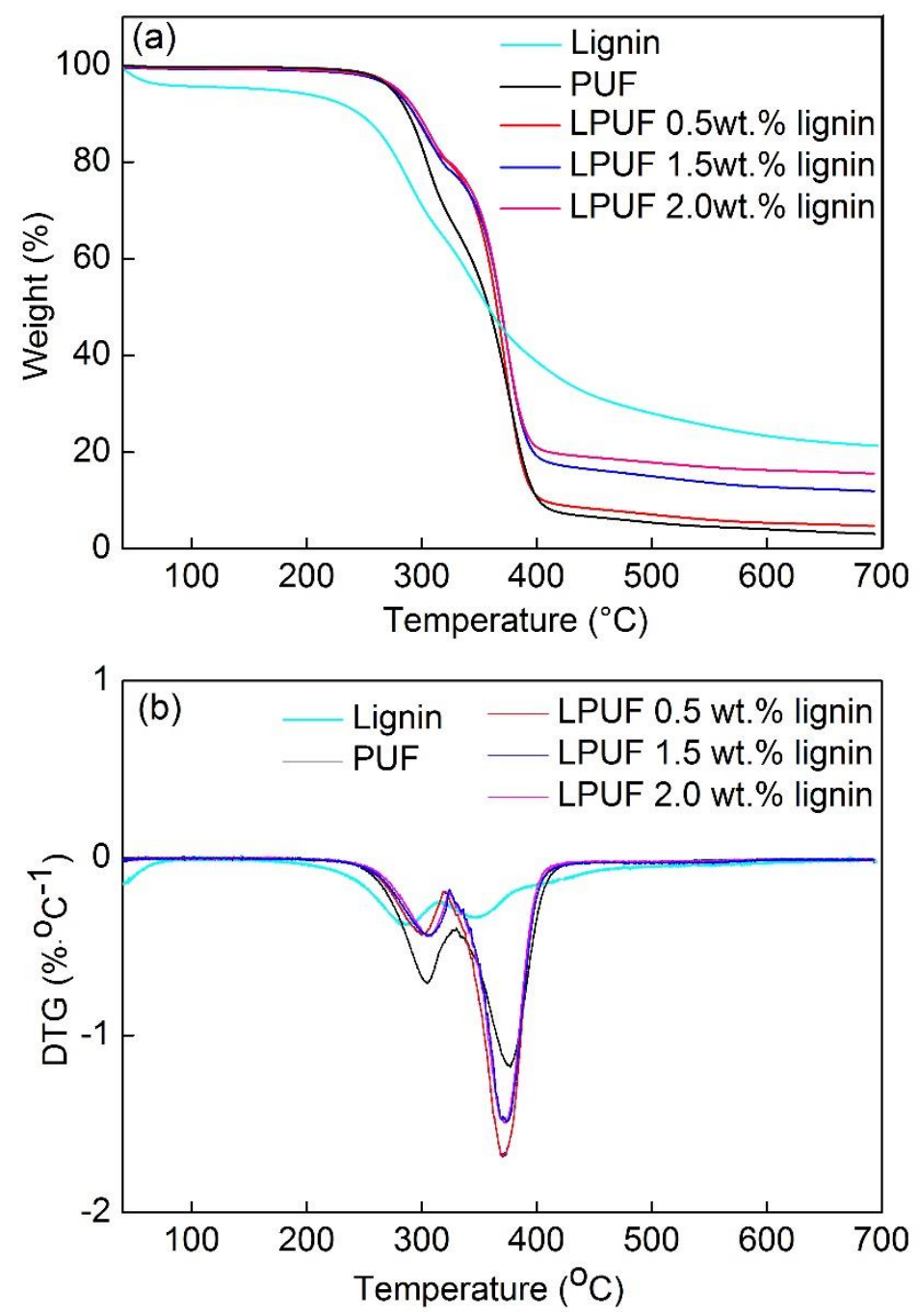

Fig. 6. TGA (a) and DTG (b) curves of the PUF and LPUFs 
Table 1. Thermogravimetric Parameters of the PUFs

\begin{tabular}{|c|c|c|}
\hline Lignin Content $(\%)$ & $\begin{array}{c}\text { Temperature } \\
(5 \% \text { of Mass Loss })\left({ }^{\circ} \mathrm{C}\right)\end{array}$ & $\begin{array}{c}\text { Temperature } \\
(50 \% \text { of Mass Loss })\left({ }^{\circ} \mathrm{C}\right)\end{array}$ \\
\hline 0 & 272.14 & 358.80 \\
\hline 0.5 & 277.43 & 365.21 \\
\hline 1.5 & 279.98 & 368.88 \\
\hline 2.0 & 280.47 & 368.97 \\
\hline
\end{tabular}

\section{Quasi Dynamic Model Analysis}

The PUFs are cellular materials that have a major role in the adsorption performance of an adsorbent. The adsorption experiments were performed with the 0.5 wt.\% LPUF as the adsorbent and with oily solvents (ethyl acetate, benzene, methyl benzene, and dimethyl benzene) as the adsorbate at $25^{\circ} \mathrm{C}$. Adsorption isotherms can determine the relationship between the adsorbate in the bulk solution and the amount adsorbed on the PUFs at a certain temperature. From Fig. 7, it was seen that the adsorption capacity increased rapidly in the first $5 \mathrm{~min}$, and then gradually increased until an equilibrium was reached. Figure 7 also revealed that the LPUF had a stronger adsorption capability than the PUF.

Adsorption kinetic analysis can offer valuable information on the adsorption mechanism by determining the adsorption rate that governs the equilibrium time of the whole adsorption process. To study the adsorption mechanism, quasi-first-order and quasisecond-order kinetic models were used to fit the experimental data. The kinetic models are shown in Fig. 7, and the corresponding parameters and the coefficients of determination $\left(\mathrm{R}^{2}\right)$ are listed in Table 2. Methyl benzene was the solvent that swelled the polyurethane networks the most, as reported by Ferrer et al. (2008).

Table 2. Kinetic Model Parameters for Oily Solvents Adsorption onto the Foams

\begin{tabular}{|c|c|c|c|c|c|c|c|c|}
\hline \multirow[b]{2}{*}{ Type } & \multirow[b]{2}{*}{ Oily Solvent } & \multirow[b]{2}{*}{$Q$} & \multicolumn{3}{|c|}{ Quasi-first-order Model } & \multicolumn{3}{|c|}{ Quasi-second-order Model } \\
\hline & & & $\begin{array}{c}K_{1} \\
\left(\min ^{-1}\right)\end{array}$ & $\begin{array}{c}Q_{e}^{f} \\
(g / g)\end{array}$ & $\mathrm{R}^{2}$ & $\begin{array}{c}K_{2} \\
(\mathrm{~g} / \mathrm{g} \min )\end{array}$ & $\begin{array}{c}Q_{e^{s}} \\
(g / g)\end{array}$ & $\mathrm{R}^{2}$ \\
\hline & Ethyl acetate & 2.18 & 0.208 & 4.621 & 0.961 & 0.162 & 13.280 & 0.999 \\
\hline & Benzene & 2.52 & 0.129 & 4.141 & 0.830 & 0.152 & 12.903 & 0.998 \\
\hline & Methyl benzene & 3.04 & 0.071 & 3.038 & 0.585 & 0.127 & 18.255 & 0.996 \\
\hline & Dimethyl benzene & 2.27 & 0.220 & 1.748 & 0.830 & 0.512 & 19.861 & 0.999 \\
\hline & Ethyl acetate & 2.37 & 0.237 & 5.115 & 0.869 & 0.186 & 17.637 & 0.999 \\
\hline & Benzene & 2.70 & 0.181 & 9.099 & 0.705 & 0.070 & 21.664 & 0.996 \\
\hline & Methyl benzene & 2.64 & 0.291 & 11.455 & 0.603 & 0.071 & 19.857 & 0.995 \\
\hline & Dimethyl benzene & 2.60 & 0.120 & 1.862 & -0.003 & 0.238 & 19.179 & 0.999 \\
\hline
\end{tabular}

${ }^{f}$ represents the quasi-first-order kinetic model; ${ }^{s}$ represents the quasi-second-order kinetic model

It was noted that the values obtained for the PUF and LPUF at the adsorption equilibrium with the quasi-first-order model $\left(Q_{\mathrm{e}}{ }^{\mathrm{f}}\right)$ were quite different from the actual values in the experiments $\left(Q_{\mathrm{e}}\right)$. This indicated that the adsorption process did not conform to the quasi-first-order kinetic model. In contrast, the values calculated from the quasisecond-order kinetic model $\left(Q_{\mathrm{e}}^{\mathrm{s}}\right)$ were sufficiently close to the $Q_{\mathrm{e}}$ values. It was concluded that the oily solvents adsorption processes of the PUF and LPUF conformed to the quasisecond-order kinetic model. This situation may be attributed to a chemical activation between oily molecules with the functional groups of the polyurethane foams (Bilir et al. 2013). The results also showed that the oily solvents adsorption process of the polyurethane 
was controlled by physical and chemical adsorption (Dufresne and Belgacem 2013; Góes et al. 2016).

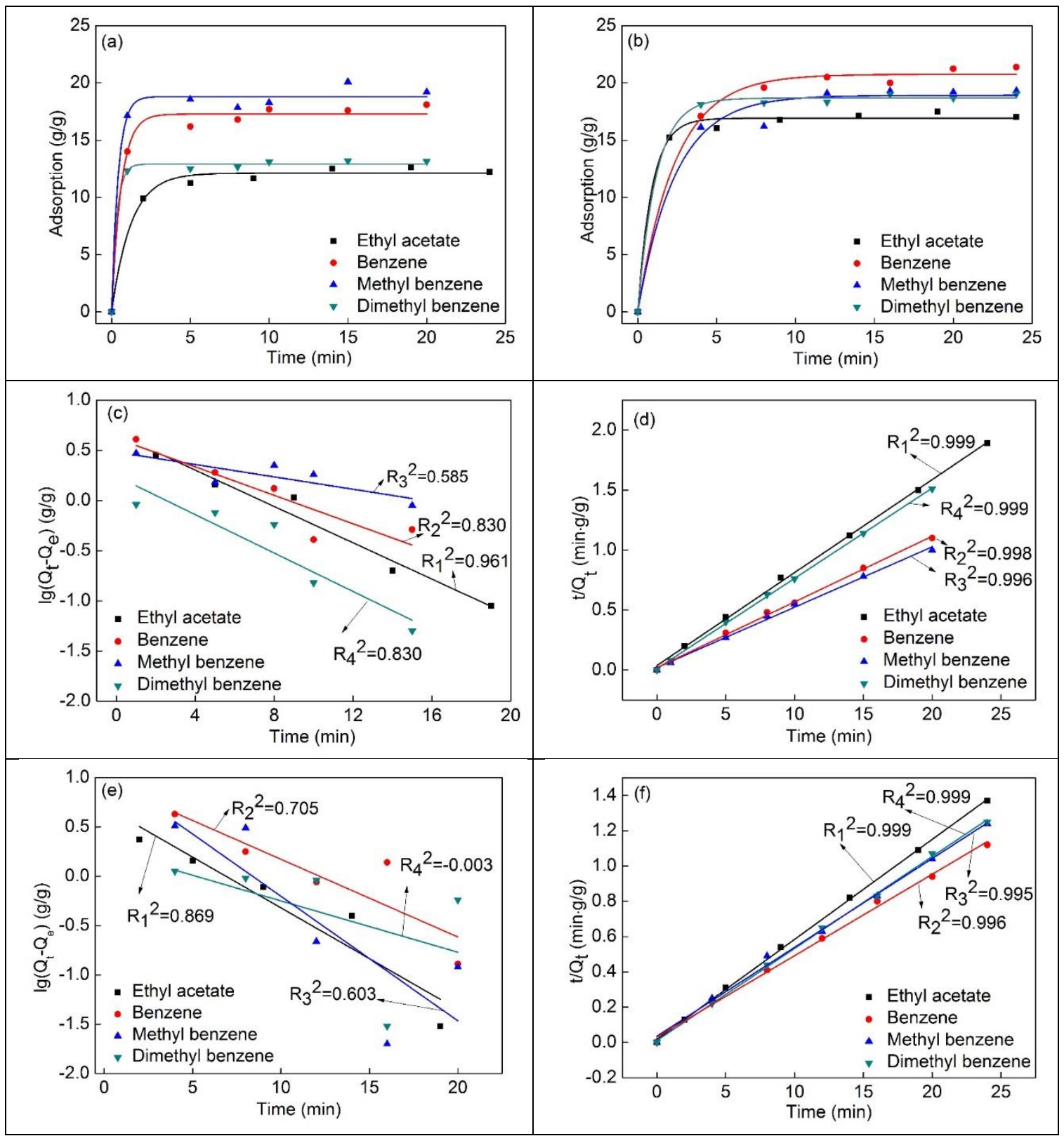

Fig. 7. Isothermal adsorption curves of the PUF and LPUF with different oily solvents at $25^{\circ} \mathrm{C}$ : (a) normal PUF and (b) LPUF (0.5 wt.\% lignin); (c) quasi-first-order and (d) quasi-second-order kinetic models of the PUFs; (e) quasi-first-order and (f) quasi-second-order kinetic models of the LPUF

The foams prepared in the present work had almost full-hole structures, which can be observed in the SEM images. The open-holes that existed complexly in the foams, as shown in Fig. 4, provided abundant "capillary-channels" and "shelters" for the entry and adsorption of oleophilic molecules. Moreover, the network skeleton can effectively support the weight of the adsorbed oily solvents and ensure an efficient retention capacity. A small amount of lignin (less than $1.0 \mathrm{wt} . \%$ ) increased the spatial cross-linking density, which 
made the pores smaller and the spatial network structure more complex. These complex skeleton structures facilitated the development of a capillary effect, which helped to achieve the purpose of oil storage. These behaviors undoubtedly increased the adsorption capacity of the adsorbate onto the polyurethane. Therefore, when the foam was in contact with the oily solvents, not only were van der Waals forces and chemical bond forces formed, but also the capillaries formed by the capillary condensation phenomenon on the surface of the polyurethane affected the oily solvents retention.

\section{Morris-Weber Model}

The fitted curves of the Morris-Weber model for the adsorption of pure PUF(a) and LPUF with 0.5 wt.\% lignin (b) are shown in Fig.8. If a straight line was obtained when $t^{1 / 2}$ was plotted against $Q_{\mathrm{t}}$, a diffusion process was active in controlling the adsorption kinetics. Furthermore, if the straight line passed through the origin, it indicated that the intraparticle diffusion was the rate-controlling step to control the adsorption process. If the origin was not passed, the adsorption process was partly controlled by diffusion, along with other adsorption stages (Vinhal et al. 2015). From Fig. 8 (a) and (b), it is apparent that the fitted line did not pass through the origin. This indicated that the adsorption process was controlled by intraparticle-diffusion and other adsorption mechanisms.
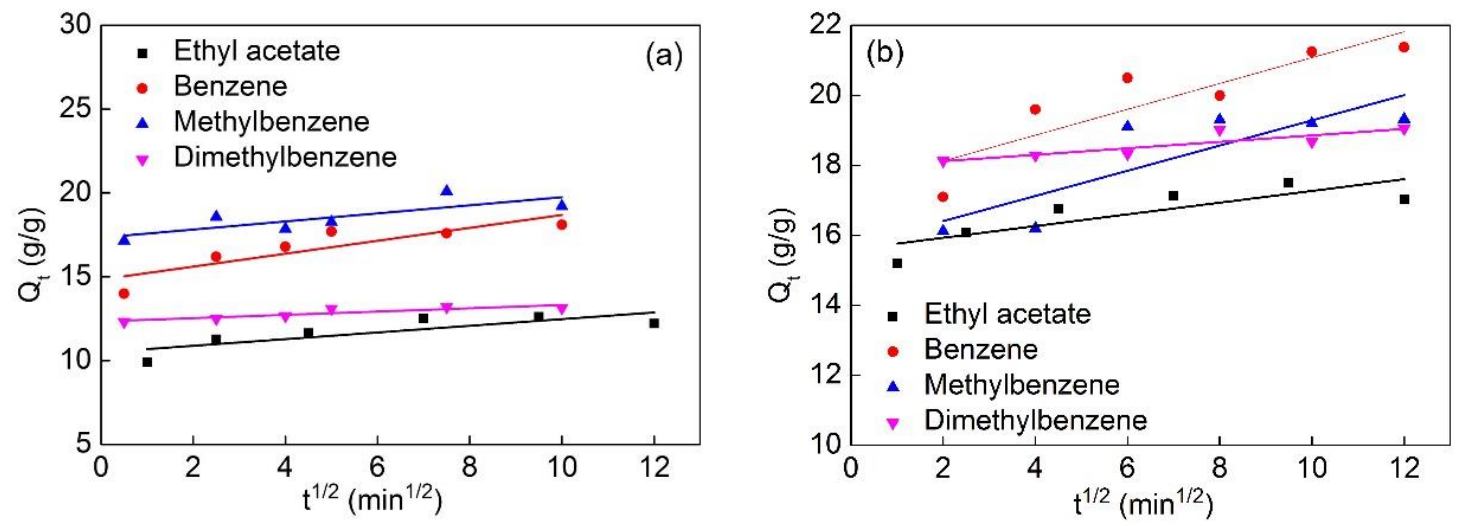

Fig. 8. Application of the Morris-Weber model for the adsorption of pure PUF (a) and LPUF with 0.5 wt.\% lignin (b).

\section{CONCLUSIONS}

1. Lignin extracted from wheat straw was added to the synthesis process of polyurethane as an additive. No remarkable differences were observed in the FT-IR spectra, which was because the small lignin content did not change the main chemical functional groups of the LPUFs.

2. The lignin content affected the cross-linking behavior and macro performances, and led to an amicable physicochemical property of the polyurethane with a suitable lignin content. Microscopic images showed smaller bubbles and thicker cellular skeletons with increased lignin content, which was associated with the increase in the crosslinking density caused by adding lignin within a proper range. The results of the TGA indicated that the thermal stabilities of the LPUFs were slightly enhanced. 
3. The mechanical tests showed that the increase in the cross-linking density was conducive to an improvement of the physical performances of the polyurethane. The compressive strength of the 0.5 wt.\% LPUF increased $40.8 \%$, and the specific compressive strength increased $61.3 \%$, compared with the normal PUF.

4. The adsorptive behaviors of the polyurethanes conformed to the quasi-second-order kinetic model. The process also involved intraparticle-diffusion. The open-holes that existed complexly in the foams provided abundant "capillary-channels" and "shelters" for the entry and adsorption of oleophilic molecules. It was concluded that LPUFs could potentially be used as adsorbing materials.

\section{ACKNOWLEDGMENTS}

The authors are grateful for the support of the China Postdoctoral Science Foundation (2017T100633 and 2016M602472), the National Natural Science Foundation of China (No. 31600471), the Natural Science Foundation of Guangdong Province (2015A030310369 and 2015A030313221), the National Key Research and Development Plan (2017YFB0307902), the 111 Plan and Guangdong Provincial Science and Technology Plan Projects (No: 2015B020241001, Research and Application of Biomass Pretreatment and Ethanol Production Technology), and the financial support of Science and Technology Plan Projects of Guangzhou city (Number: 201504010013, Name: Study on Quality Intelligent Control of Modern Paper Machine and Energy-saving Technology with Equipment).

\section{REFERENCES CITED}

ASTM D726-12 (2012). "Standard test methods for sorbent performance of abdorbents," ASTM International, West Conshohocken, PA.

ASTM D792-08 (2008). "Standard test methods for density and specific gravity (relative density) of plastics by displacement," ASTM International, West Conshohocken, PA.

ASTM D1621-10 (2010). "Standard test method for compressive properties of rigid plastics," ASTM International, West Conshohocken, PA.

ASTM D1623-09 (2009). "Standard test method for tensile and tensile adhesion properties of rigid cellular plastics," ASTM International, West Conshohocken, PA.

ASTM F726-99 (1999). "Standard test method for sorbent performance of adsorbents," ASTM International, West Conshohocken, PA.

Baillères, H., Castan, M., Monties, B., Pollet, B., and Lapierre, C. (1997). "Lignin structure in Buxus sempervirens reaction wood," Phytochemistry 44(1), 35-39. DOI: 10.1016/S0031-9422(96)00499-2

Bilir, M. H., Şakalar, N., Acemioğlu, B., Baran, E., and Alma, M. H. (2013). "Sorption of remazol brilliant blue $\mathrm{r}$ onto polyurethane - type foam prepared from peanut shell," Journal of Applied Polymer Science 127(6), 4340-4351. DOI: 10.1002/app.37614

Carriço, C. S., Fraga, T., and Pasa, V. M. D. (2016). "Production and characterization of polyurethane foams from a simple mixture of castor oil, crude glycerol and untreated 
lignin as bio-based polyols," Eur. Polym. J. 85, 53-61. DOI:

10.1016/j.eurpolymj.2016.10.012

Cateto, C. A., Barreiro, M. F., Ottati, C., Lopretti, M., Rodrigues, A. E., and Belgacem, M. N. (2014). "Lignin-based rigid polyurethane foams with improved biodegradation," J. Cell. Plast. 50(1), 81-95. DOI: 10.1177/0021955X13504774

Cinelli, P., Anguillesi, I., and Lazzeri, A. (2013). "Green synthesis of flexible polyurethane foams from liquefied lignin," Eur. Polym. J. 49(6), 1174-1184. DOI: 10.1016/j.eurpolymj.2013.04.005

Crini, G., Peindy, H. N., Gimbert, F., and Robert, C. (2007). "Removal of C.I. basic green 4 (malachite green) from aqueous solutions by adsorption using cyclodextrinbased adsorbent: Kinetic and equilibrium studies," Separation \& Purification Technology 53(1), 97-110. DOI: 10.1016/j.seppur.2006.06.018

dos Santos, L. M., Carone, C. L. P., Dullius, J., Ligabue, R., and Einloft, S. (2013). "Using different catalysts in the chemical recycling of waste from flexible polyurethane foams," Polímeros 23(5), 608-613. DOI: 10.4322/polimeros.2013.096

Dufresne, A., and Belgacem, M. N. (2013). "Cellulose-reinforced composites: From micro-to nanoscale," Polimeros-ciencia E Tecnologia 23(3), 277-286. DOI: 10.4322/polimeros.2010.01.001-License: CC BY 4.0

Dworakowska, S., Bogdal, D., Zaccheria, F., and Ravasio, N. (2014). "The role of catalysis in the synthesis of polyurethane foams based on renewable raw materials," Catal. Today 223, 148-156. DOI: 10.1016/j.cattod.2013.11.054

Estrin, Y. I., Badamshina, E. R., Grishchuk, A. A., Kulagina, G. S., Lesnichaya, V. A., Ol'khov, Y. A., Ryabenko, A. G., and Sul'yanov, S. N. (2012). "Properties of nanocomposites based on crosslinked elastomeric polyurethane and ultrasmall additives of single-wall carbon nanotubes," Polymer Science Series A 54(4), 290-298. DOI: $10.1134 / \mathrm{S} 0965545 \mathrm{X} 12040037$

Fan, Q., and Xiao, C. (2010). "Effects of crosslinking density on structure and properties of interpenetrating polymer networks from polyurethane and nitroguar gum," Polym. Composite. 29(7), 758-767. DOI: 10.1002/pc.20451

Flory, P. J., and Rehner Jr., J. (1943). "Statistical mechanics of crosslinked polymer networks I. Rubberlike elasticity," J. Chem. Phys. 11(11), 512-520. DOI: $10.1063 / 1.1723792$

Góes, M. M., Keller, M., Oliveira, V. M., Villalobos, L. D. G., Moraes, J. C. G., and Carvalho, G. M. (2016). "Polyurethane foams synthesized from cellulose-based wastes: kinetics studies of dye adsorption," Industrial Crops \& Products 85, 149-158. DOI: $10.1016 /$ j.indcrop.2016.02.051

Gui, X., Li, H., Wang, K., Wei, J., Jia, Y., Li, Z., Fan, L., Cao, A., Zhu, H., and Wu, D. (2011). "Recyclable carbon nanotube sponges for oil absorption," Acta Mater. 59(12), 4798-4804. DOI: 10.1016/j.actamat.2011.04.022

Hakim, A. A. A., Nassar, M., Emam, A., and Sultan, M. (2011). "Preparation and characterization of rigid polyurethane foam prepared from sugar-cane bagasse polyol," Mater. Chem. Phys. 129(1-2), 301-307. DOI:

10.1016/j.matchemphys.2011.04.008

Hatakeyama, H., Kosugi, R., and Hatakeyama, T. (2008). "Thermal properties of ligninand molasses-based polyurethane foams," J. Therm. Anal. Calorim. 92(2), 419-424. DOI: $10.1007 / \mathrm{s} 10973-007-8963-1$

Huang, S.-L., and Lai, J.-Y. (1997). "Structure-tensile properties of polyurethanes," Eur. Polym. J. 33(10-12), 1563-1567. DOI: 10.1016/S0014-3057(97)00058-X 
Huo, S.-P., Nie, M.-C., Kong, Z.-W., Wu, G.-M., and Chen, J. (2012). “Crosslinking kinetics of the formation of lignin-aminated polyol-based polyurethane foam," $J$. Appl. Polym. Sci. 125(1), 152-157. DOI: 10.1002/app.35401

Jeong, H., Park, J., Kim, S., Lee, J., and Ahn, N. (2013). "Compressive viscoelastic properties of softwood kraft lignin-based flexible polyurethane foams," Fibers and Polymers 14(8), 1301-1310. DOI: 10.1007/s12221-013-1301-2

Kumari, S., Chauhan, G. S., Monga, S., Kaushik, A., and Ahn, J.-H. (2016). "New ligninbased polyurethane foam for wastewater treatment," RSC Advances 6(81), 7776877776. DOI: 10.1039/C6RA13308H

Li, C., Liu, L., and Zhu, C. (2011). "Characterization of renewable PUF and preparation of polyurethane foam composites with alkali lignin/renewable PUF," The Open Materials Science Journal 11(5), 130-133. DOI: 10.2174/1874088X01105010130

Li, H., Liu, L., and Yang, F. (2012). "Hydrophobic modification of polyurethane foam for oil spill cleanup," Mar. Pollut. Bull. 64(8), 1648-1653. DOI: 10.1016/j.marpolbul.2012.05.039

Li, H. -Q., Shao, Q., Luo, H., and Xu, J. (2016). "Polyurethane foams from alkaline lignin-based polyether polyol,” J. Appl. Polym. Sci. 133(14). DOI: 10.1002/app.43261

Li, Y., and Ragauskas, A. J. (2012). "Ethanol organosolv lignin-based rigid polyurethane foam reinforced with cellulose nanowhiskers," RSC Advances 2(8), 3347-3351. DOI: 10.1039/C2RA00646D

Luo, X., Mohanty, A., and Misra, M. (2013). "Lignin as a reactive reinforcing filler for water-blown rigid biofoam composites from soy oil-based polyurethane," Industrial Crops \& Products 47(3), 13-19. DOI: 10.1016/j.indcrop.2013.01.040

Oribayo, O., Feng, X., Rempel, G. L., and Pan, Q. (2017). "Synthesis of lignin-based polyurethane/graphene oxide foam and its application as an absorbent for oil spill clean-ups and recovery," Chemical Engineering Journal, 191-202. DOI: 10.1016/j.cej.2017.04.054

Mahmood, N., Yuan, Z., Schmidt, J., Tymchyshyn, M., and Xu, C. (2016a). "Hydrolytic liquefaction of hydrolysis lignin for the preparation of bio-based rigid polyurethane foam," Green Chem. 18(8), 2385-2398. DOI: 10.1039/C5GC02876K

Mahmood, N., Yuan, Z., Schmidt, J., and Xu, C. (2016b). "Depolymerization of lignins and their applications for the preparation of polyols and rigid polyurethane foams: A review," Renew. Sust. Energ. Rev. 60, 317-329. DOI: 10.1016/j.rser.2016.01.037

Mathew, A., Kurmvanshi, S., Mohanty, S., and Nayak, S. K. (2017). "Influence of diisocyanate, glycidol and polyol molar ratios on the mechanical and thermal properties of glycidyl - terminated biobased polyurethanes," Polymer International. DOI: $10.1002 /$ pi.5412

Paberza, A., Cabulis, U., and Arshanitsa, A. (2014). "Wheat straw lignin as filler for rigid polyurethane foams on the basis of tall oil amide," Polimery-W 59(6), 477-481. DOI: 10.14314/polimery.2014.477

Pan, X., and Saddler, J. N. (2013). "Effect of replacing polyol by organosolv and kraft lignin on the property and structure of rigid polyurethane foam," Biotechnology for Biofuels 6, 12-21. DOI: 10.1186/1754-6834-6-12

Putz, K. W., Palmeri, M. J., Cohn, R. B., Andrews, R., and Brinson, L. C. (2008). "Effect of cross-link density on interphase creation in polymer nanocomposites," Macromolecules 41(18), 6752-6756. DOI: 10.1021/ma800830p 
Qiu, H., Lv, L., Pan, B.-c., Zhang, Q.-j., Zhang, W.-m., and Zhang, Q.-x. (2009). "Critical review in adsorption kinetic models," Journal of Zhejiang UniversitySCIENCE A 10(5), 716-724. DOI: 10.1631/jzus.A0820524

Qu, J. Y., Han, Q., Gao, F., and Qiu, J. S. (2017). “Carbon foams produced from ligninphenol-formaldehyde resin for oil/water separation," New Carbon Materials 32(1), 86-91. DOI: 10.1016/S1872-5805(17)60109-4

Rahman, M. M., Zahir, M. H., and Han, D. K. (2016). "Synthesis and properties of waterborne polyurethane (wbpu)/modified lignin amine (mla) adhesive: A promising adhesive material," Polymers 8(9), 318. DOI: 10.20944/preprints201608.0102.v1

Saito, T., Perkins, J. H., Jackson, D. C., Trammel, N. E., Hunt, M. A., and Naskar, A. K. (2013). "Development of lignin-based polyurethane thermoplastics," RSC Advances 3(44), 21832-21840. DOI: 10.1039/C3RA44794D

Santos, O. S., Coelho, d. S. M., Silva, V. R., Mussel, W. N., and Yoshida, M. I. (2016). "Polyurethane foam impregnated with lignin as a filler for the removal of crude oil from contaminated water," Journal of Hazardous Materials 406-413. DOI: 10.1016/j.jhazmat.2016.11.004

Tian, X., Wang, B., Wang, B., Li, J., and Chen, K. (2017). "Structural characterization of lignin isolated from wheat-straw during the alkali cooking process," BioResources 12(2), 2407-2420. DOI: 10.15376/biores.12.2.2407-2420

Vanholme, R., Demedts, B., Morreel, K., Ralph, J., and Boerjan, W. (2010). "Lignin biosynthesis and structure," Plant Physiol. 153(3), 895-905. DOI: 10.1104/pp.110.155119

Valero, M., Pulido, J., Ramirez, A., Cheng, Z. (2009). 'Determination of crosslink density of polyurethanes obtained from castor oil modified by transesterification," Polimeros-Ciencia E Tecnologia 19(1),14-21.

Vinhal, J. O., Lage, M. R., Carneiro, J. W. M., Lima, C. F., and Cassella, R. J. (2015). "Modeling, kinetic, and equilibrium characterization of paraquat adsorption onto polyurethane foam using the ion-pairing technique," Journal of Environmental Management 156(156), 200. DOI: 10.1016/j.jenvman.2015.03.022

Xue, B.-L., Wen, J.-L., and Sun, R.-C. (2014). "Lignin-based rigid polyurethane foam reinforced with pulp fiber: Synthesis and characterization," ACS Sustainable Chemistry \& Engineering 2(6), 1474-1480. DOI: 10.1021/sc5001226

Yang, L., Wang, X., Cui, Y., Tian, Y., Chen, H., and Wang, Z. (2015). "Modification of renewable resources - lignin - by three chemical methods and its applications to polyurethane foams," Polymers for Advanced Technologies 25(10), 1089-1098. DOI: 10.1002/pat.3356

Yu, Y. H., Choi, I., Nam, S., and Dai, G. L. (2014). "Cryogenic characteristics of chopped glass fiber reinforced polyurethane foam," Composite Structures 107(1), 476-481. DOI: 10.1016/j.compstruct.2013.08.017

Zhang, C., Wu, H., and Kessler, M. R. (2015). "High bio-content polyurethane composites with urethane modified lignin as filler," Polymer 69(1), 52-57. DOI: 10.1016/j.polymer.2015.05.046

Zhu, G., Wang, G., and Hu, C. P. (2011). "Effect of crosslink density on the structures and properties of aliphatic polyurethancmer," ACTA Polym. Sin. 11(3) 274-280. DOI: 10.3724/SP.J.1105.2011.10041 
Zhu, H., Peng, Z., Chen, Y., Li, G., Wang, L., Tang, Y., Pang, R., Khan, Z. U., and Wan, P. (2014). "Preparation and characterization of flame retardant polyurethane foams containing phosphorus-nitrogen-functionalized lignin," RSC Advances 4(98), 5527155279. DOI: 10.1039/C4RA08429B

Article submitted: June 9, 2017; Peer review completed: September 3, 2017; Revised version received and accepted: September 24, 2017; Published: October 2, 2017.

DOI: $10.15376 /$ biores. 12.4.8653-8671 